\title{
PELATIHAN PEMBUATAN MEDIA PEMBELAJARAN DI SEKOLAH YAYASAN PEMBINAAN ANAK CACAT (YPAC) PALEMBANG
}

\author{
Stefanus Setyo Wibagso \\ Fakultas Sains dan Teknologi, Universitas Katolik Musi Charitas \\ email: setyo.wibagso@ukmc.ac.id \\ Ria Triayomi \\ Fakultas Humaniora dan Ilmu Pendidikan, Universitas Katolik Musi Charitas \\ email: riatriayomi@ukmc.ac.id \\ Ignasius Putera Setiahati \\ Fakultas Humaniora dan Ilmu Pendidikan, Universitas Katolik Musi Charitas \\ email: ig_putra@ukmc.ac.id \\ Sukarman \\ Fakultas Humaniora dan Ilmu Pendidikan, Universitas Katolik Musi Charitas \\ email: sukarman@ukmc.ac.id \\ Masayu Jamilah \\ Fakultas Sains dan Teknologi, Universitas Katolik Musi Charitas \\ email: masayu@ukmc.ac.id
}

\begin{abstract}
Media pembelajaran menjadi bagian penting dari sarana dan prasarana pembelajaran di sekolah untuk membantu siswa belajar baik secara abstrak maupun secara konkret/nyata. Menurut Faizal (2010), media pembelajaran membantu proses pembelajaran menjadi lebih menarik dan membangkitkan minat siswa dalam mendalami suatu materi. Namun, pada kenyataannya seringkali didapati di lapangan ketersediaan media pembelajaran sangatlah terbatas dan tidak banyak guru yang tertarik dan kreatif dalam membuat media pembelajaran. Hal ini dikarenakan banyak hal seperti keterbatasan dana, waktu, pengetahuan, serta keengganan guru dalam membuat media pembelajaran. Oleh karena itu dirasa perlu untuk membekali para guru dalam membuat media pembelajaran yang mudah dan murah berbasis ICT. Pembekalan ini diberikan untuk para guru di sekolah YPAC di Palembang yang sangat membutuhkan. Target dan luaran dalam kegiatan ini adalah menghasilkan media pembelajaran anak berkebutuhan khusus yang sederhana dan melatih kreativitas guru dalam membuat dan menggunakan media pembelajaran tersebut. Pelatihan dasar yang diberikan oleh tim dosen Program Studi SI dan PGSD Universitas Katolik Musi Charitas ini sebagai tahap awal untuk merangsang ketertarikan dan kerjasama antara guru agar lebih kreatif dalam membuat media pembelajaran sederhana berbasis ICT sekaligus memperluas pengetahuan guru. Pelatihan diberikan dalam bentuk pelatihan dasar dalam membuat media pembelajaran secara sederhana bagi anak berkebutuhan khusus serta penggunaannya dalam pembelajaran. Metode yang dipakai adalah ceramah, tanya jawab, demonstrasi, dan eksperimen. Harapannya, seluruh peserta memiliki bekal yang cukup untuk membuat media pembelajaran sesuai karakteristik siswa.
\end{abstract}

Kata Kunci: Kreatif, Media Pembelajaran, Menarik, Pelatihan. 


\begin{abstract}
ABSTRAK
Learning media is an important part of learning facilities and infrastructure in schools to help students to learn abstractly and concretely. According to Faizal (2010), learning media helps the learning process become more interesting and arises students' interest in exploring a material. However, in reality it is often found in schools that learning media is very limited and not many teachers are interested and creative in making learning media. They are many reasons such as limited funds, time, knowledge, and the reluctance of teachers to make learning media. Therefore it is necessary to equip teachers in making easy and cheap ICT-based learning media. This training was given to teachers at the YPAC school in Palembang who were in great need. The targets and outputs of this activity are to produce simple learning media for children with special needs and to train teachers' creativity in making and using these learning media. The basic training by a team of lecturers at the SI and PGSD Study Program at Musi Charitas Catholic University is the first step to stimulate interest and collaboration between teachers to be more creative in making simple ICT-based learning media as well as expanding teacher knowledge. The training is provided in the form of basic training in making simple learning media for children with special needs and how to use them in learning. The methods used are lectures, questions and answers, demonstrations, and experiments. Hopefully, all participants have sufficient skills to create learning media according to student characteristics.
\end{abstract}

Keywords: Creative, Learning Media, Interesting, Training.

\section{PENDAHULUAN}

Metode dan media pembelajaran yang tepat sangat dibutuhkan untuk mencapai tujuan pembelajaran secara maksimal yang dapat meningkatkan kualitas pendidikan. Melalui penggunaan media pembelajaran yang tepat guru dapat memberikan pengenalan materi yang disesuaikan dengan taraf berpikir muridnya. Hal ini semakin dipermudah dengan adanya media pembelajaran berbasis teknologi yang semakin mempermudah aktivitas belajar-mengajar karena mampu meningkatkan kreatifitas dan kemudahan dalam berkomunikasi (Cholik, 2017).

Menurut Sudjana (2009), media adalah suatu alat yang dapat diserap oleh mata dan telinga dengan tujuan membantu guru agar proses belajar-mengajar siswa lebih efektif dan efisien. Namun, pada kenyataannya tidak banyak sekolah yang menyediakan media pembelajaran di kelas-kelas termasuk di sekolah mitra. Ada banyak faktor penyebab, antara lain mengajar menggunakan media dianggap lebih merepotkan, kebiasaan mengajar dengan metode ceramah, keterbatasan pengetahuan guru tentang alat peraga pembelajaran, serta kurangnya ketersediaan dana dan waktu untuk membuat. Padahal, media pembelajaran dapat meningkatkan ketertarikan siswa pada suatu materi tertentu (Nurita, 2018).

Sekolah yang menjadi mitra dalam pelatihan ini adalah Sekolah YPAC di Palembang. YPAC adalah sekolah swasta yang peduli dengan anak-anak berkebutuhan khusus. YPAC menjadi karya sosial yang tidak bonafit dan secara finansial dan SDM cukup terbatas. Dari wawancara langsung dengan Kepala Sekolah diperoleh informasi bahwa ketersediaan media pembelajaran dan kemampuan SDM khususnya guru sangat terbatas. Sehingga pada saat pembelajaran berlangsung, guru cenderung tidak menggunakan media. Padahal, penggunaan media pembelajaran sangat membantu untuk melayani anak berkebutuhan khusus dalam pembelajaran (Undang- Undang no. 8 Tahun 2016). Dari uraian ini kita tahu bahwa Sekolah YPAC Palembang membutuhkan bekal berupa pengetahuan pembuatan media pembelajaran. Sesuai dengan perkembangan zaman dan lebihlebih dalam situasi pendemi ini, bentuk 
pembekalan yang dibutuhkan adalah membuat media pembelajaran sederhana dalam bentuk video pembelajaran dengan menggunakan laptop dan smartphone. Dan media pembelajaran dalam bentuk video sangat cocok untuk anak melienial atau generasi Z (Alfiani, 2016). Oleh karena itu, tim dosen UKMC ingin berbagi pengetahuan dalam bentuk pelatihan pembuatan media pembelajaran sederhana berbasis ICT bagi guru Sekolah YPAC Palembang.

Media pembelajaran memiliki fungsi yaitu: 1) memberikan pedoman/arah untuk mencapai tujuan; 2) meningkatkan kualitas pelajaran; 3) memudahkan kendali pengajar terhadap materi pelajaran; 4) meningkatkan motivasi pembelajar; 5) pembelajar dapat memahami materi pelajaran dengan sistematis dan variatif; 6) membangkitkan rasa percaya diri seorang pengajar.

Tujuan kegiatan ini memberikan bekal berupa pengetahuan tentang pembuatan media pembelajaran dalam bentuk video pembelajaran sederhana berbasis ICT dengan menggunakan laptop dan smartphone bagi guru di Sekolah YPAC Palembang. Setelah pelatihan diharapkan para guru mampu membuat beberapa jenis media pembelajaran yang dapat digunakan pada saat pembelajaran.

\section{METODE PELAKSANAAN}

Kegiatan pelatihan ini dilaksanakan di Sekolah YPAC Palembang yang beralamat di Jalan Mr. R. Sudarman Ganda Subrata No.2727, Sukamaju, Kec. Sako, Palembang. Adapun tahapan yang dibuat tim dosen dalam pengabdian ini, adalah:

\section{a. Tahap Persiapan}

Tahap persiapan yang dilakukan meliputi observasi awal dan pemantapan serta penentuan lokasi dan sasaran. Kemudian dilanjutkan penyusunan bahan pendampingan yang meliputi materi berupa slide power point tentang pentingnya media pembelajaran anak berkebutuhan khusus. Di samping itu tim dosen juga berlatih dan belajar bersama membuat media pembelajaran selama beberapa hari sebelum kegiatan dilaksanakan. Tahap persiapan ini dilakukan kurang lebih tiga bulan.

\section{b. Tahap Pelaksanaan Kegiatan}

Tahap pelaksanaan pendampingan dilakukan selama sehari dengan durasi lebih kurang tiga jam dari jam 09.00 sampai 12.00 kemudian dilanjutkan pendampingan secara online. Hal ini dilakukan mengingat situasi pandemi untuk membatasi perjumpaan. Pertama-tama, tim dosen memberikan materi tentang pentingnya media pembelajaran, kemudian dilanjutkan dengan pengenalan berbagai jenis media pembelajaran anak berkebutuhan khusus, setelah itu membahas tentang cara pembuatan dan petunjuk pemakaian. Setelah selesai semua introduksi, guru langsung praktik. Pertama-tama guru diajak mendownload aplikasi yang dibutuhkan. Setelah itu guru diminta untuk merekam video kegiatan sederhana mereka yaitu penerapan 5M (Memakai masker, Mencuci tangan, Menjaga jarak, Menghindari kerumunan, dan Mengurangi mobilitas). Kemudian video-video tersebut diedit menggunakan laptop atau langsung di smartphone. Setelah pelatihan, tim dosen tetap memberikan pendampingan kepada para guru secara online karena waktu tiga jam pendampingan dianggap sangat terbatas. Para guru diharapkan melanjutkan pembuatan media di rumah masing-masing dan jika ingin membuat media pembelajaran lain tim dosen siap membantu.

Ada beberapa metode yang dipakai dalam pelatihan ini:

\section{a. Metode ceramah/ presentasi}

Metode ceramah dipilih untuk memberikan penjelasan tentang pentingnya media pembelajaran, berbagai jenis media pembelajaran anak berkebutuhan khusus, cara pembuatan dan petunjuk pemakaian media pembelajaran dalam bentuk video pembelajaran sederhana dengan menggunakan ICT.

\section{b. Metode diskusi}

Guru dan tim dosen mendiskusikan hal-hal terkait dengan pembuatan media pembelajaran dalam bentuk video pembelajaran sederhana 
dengan menggunakan ICT di Sekolah YPAC Palembang.

\section{c. Metode demonstrasi}

Tim dosen juga mendemonstrasikan cara download aplikasi, pembuatan media pembelajaran yang kemudian diikuti dan dicontoh oleh para guru.

d. Metode eksperimen/ praktik,

Guru melakukan praktik langsung pembuatan media pembelajaran dalam bentuk video pembelajaran sederhana berbasis ICT setelah materi selesai dipaparkan. Tim dosen dan mahasiwa mendampingi dan membantu para guru.

Selama kegiatan pelatihan ini berlangsung, pihak mitra menyediakan tempat dan mempersiapkan para peserta/guru yang mengikuti pelatihan.

\section{Tabel 1. Jadwal Pendampingan}

\begin{tabular}{|c|l|c}
\hline Waktu (WIB) & \multicolumn{1}{|c|}{ Kegiatan } & Narasumber \\
\hline $09.00-09.10$ & $\begin{array}{l}\text { Pembukaan, Doa, Sambutan dari Sekolah } \\
\text { YPAC }\end{array}$ & YPAC \\
\hline $09.10-09.30$ & $\begin{array}{l}\text { Materi membuat bahan ajar berupa video } \\
\text { tutorial sebagai media pembelajaran }\end{array}$ & Tim Dosen \\
\hline $09.30-11.00$ & Praktek & Tim Dosen \\
\hline $11.00-12.00$ & Kuisioner,Penugasan, Doa, Foto bersama & Tim Dosen \\
\hline
\end{tabular}

\section{HASIL DAN PEMBAHASAN}

Tim pengabdian ini terdiri dari lima orang dosen dan dua mahasiswa. Kegiatan pendampingan dilakukan sehari dengan tatap muka kemudian dianjutkan dengan pendampingan secara online. Tatap muka dilaksanakan pada tanggal 5 April 2021. Sesuai dengan rencana, kegiatan ini membekali para guru Sekolah YPAC untuk membuat media pembelajaran berbasis ICT berupa video mengunakan laptop dan smartphone. Peserta berjumlah 20 guru terdiri dari kelompok guru kelas $\mathrm{C}$ berjumlah 3, kelompok guru kelas $\mathrm{C} 1$ berjumlah 4, kelompok guru kelas B berjumlah 5 dan kelompok guru kelas D berjumlah 6 serta kepala sekolah dan wakil yang mendampingi.
Program pengabdian pada masyarakat berupa pendampingan bagi guru di Sekolah YPAC Palembang ini diharapkan dapat menambah pengetahuan dan keterampilan para guru serta meningkatkan rasa percaya diri dalam menjalankan profesinya. Guru akan lebih semangat dan termotivasi untuk mengembangkan diri. Hasil pendampingan ini tentu bermanfaat juga bagi sekolah karena meningkatkan kualitas guru dan pembelajaran. Proses belajar mengajarnya akan lebih menarik dengan aplikasi yang mendukung yang lebih bervariasi, murah, dan mudah. Di samping itu dengan adanya pendampingan ini akan menambah keterampilan guru dalam menyiapkan bahan ajar sehingga akan mendukung kemampuan guru dalam menyiapkan program sertifikasi yang mau tidak mau harus dilakukan (Syahroni, 2020).

Dalam pelatihan ini, sofware yang dipakai adalah Movie Maker. Movie maker adalah salah satu aplikasi atau software yang dapat dimanfaatkan untuk tetap produktif meski dilakukan dari rumah. Windows Movie Maker atau disingkat WMM adalah sebuah program editing video yang sederhana, didesain untuk pemilik $P C$ dengan sedikit pengalaman untuk membuat video rumahan. Sebenarnya Microsoft sudah memperkenalkan fasilitas WMM ini di Windows Millennium Edition (Me) beberapa waktu lalu. Namun waktu itu masih sebagai tambahan atau Accessories. Movie maker adalah perangkat lunak yang merupakan bagian dari windows live essential. Fungsi utama software movie maker ini adalah untuk melakukan olah digital terhadap cuplikancuplikan gambar bergerak (video). Banyak Fitur-fitur yang tersedia dalam software movie maker misalnya penambahan animasi atau effect visual, menambahkan caption tulisan dalam video serta penambahan musik atau lagu (Rival, 2016).

Keistimewaan Windows Movie Maker ini mampu bekerja dengan baik pada pada sistem operasi berbasis windows, baik itu versi 7,8 maupun 10. Walapun hanya dengan menggunakan versi gratis sekalipun hasil video yang dihasilkan sudah sangat baik. Pada versi pro, Windows Movie Maker menawarkan fitur yang lebih baik terutama dalam hasil output 
video seperti fitur slow and fast motion, bitrate settings, dan $4 K$ and $60 \mathrm{fps}$ video output. Selain itu pengguna dapat membuka semua fitur yang dikunci pada versi free-nya (Microsoft, 2021).

Dalam praktik pembuatan video peserta dibagi dalam kelompok. Setiap kelompok diminta untuk membuatkan video mengenai informasi 5M. Setiap kelompok bertugas untuk mevideokan setiap anggota mengenai cara mencuci tangan dengan benar, memakai masker dengan benar, dan menjaga jarak dengan benar, menjauhi kerumunan serta mengurangi mobilitas. Video dibuat dengan smatphone kemudian di edit dengan aplikasi movie maker.

Peserta antusias melihat aplikasi movie maker yang bisa membuat media pembelajaran. Tim dosen memberikan materi tentang pengetahuan dasar mengenai fitur animations dan visual effects. Kemampuan peserta dilihat dari penguasaan materi masih kurang dikarenakan guru-guru termasuk guru senior dengan kemampuan yang berbeda-beda. Dari pertanyaan-pertanyaan juga tampak bahwa guru memang belum menguasai media pembelajaran berbasis ICT. Berbagai pertanyaan diajukan secara antusias oleh para peserta dalam sesi tanya jawab. Secara garis besar inti dari pertanyaan para peserta adalah aplikasi yang cocok untuk anak berkebutuhan khusus yang baik. Dari kuesioner awal, juga kelihatan bahwa tidak ada guru yang menggunakan video sebagai media pembelajaran dan hanya 3 guru yang bisa menggunakan aplikasi membuat video tetapi tidak pernah digunakan untuk pembelajaran.

Peserta lebih antusias lagi ketika langsung praktik. Kendala yang dihadapi pada proses pendampingan yaitu ada beberapa peserta yang tidak bisa menggunakan aplikasi karena kapasitas laptop dan smartphone tidak mendukung dan jaringan internet tidak stabil. Ada beberapa peserta yang sudah mempunyai aplikasi movie maker tapi tidak tahu cara menggunakan. Sehingga pada prosesnya tim dosen memulai dengan mengecek laptop dan smartphone masing-masing peserta.

Di awal pelatihan, tim dosen memberikan kuesioner untuk melihat kemampuan awal para guru. Dan diakhir kembali diberikan post-test untuk melihat perkembangan dari pelatihan.
Table 2: Pre-test

\begin{tabular}{l|l|c|c|}
\hline No & \multicolumn{1}{|c|}{ Pernyataan } & Ya & Tidak \\
\hline 1 & $\begin{array}{l}\text { Apakah anda mempersiapkan media pembelajaran anda pada setiap } \\
\text { pertemuan? }\end{array}$ & 20 & 0 \\
\hline 2 & Apakah anda menyam paikan materi video? & 0 & 20 \\
\hline 3 & $\begin{array}{l}\text { Apakah anda mengumpulkan materi pembelajaran dalam bentuk video setiap } \\
\text { anda mengajar? }\end{array}$ & 2 & 18 \\
\hline 4 & Apakah anda membuat rencana materi dalam kurun waktu tertentu? & 19 & 1 \\
\hline 5 & Apakah anda tahu membuat video? & 0 & 20 \\
\hline 6 & $\begin{array}{l}\text { Apakah anda pernah menggunakan aplikasi di smartphone untuk membuat } \\
\text { media pembelajaran bentuk video dalam mengajar? }\end{array}$ & 0 & 20 \\
\hline 7 & Apakah anda bisa menggunakan media pembelajaran bentuk video? & 3 & 17 \\
\hline 8 & Apakah anda pernah membuat video pembelajaran? & 0 & 20 \\
\hline \hline
\end{tabular}

Tabel 3: Post-test

\begin{tabular}{l|l|l|l|}
\hline \multicolumn{1}{c|}{ Pernyataan } & \multicolumn{1}{|c|}{ Ya } & Tidak \\
\hline & Saya berencana mempersiapkan video pembelajaran pada setiap pertemuan & 20 & 0 \\
\hline & Saya akan menyampaikan materi menggunakan video pembelajaran & 17 & 3 \\
\hline Saya akan mengumpulkan materi video pembelajaran setiap mengajar & 15 & 5 \\
\hline Saya membuat rencana materi dalam kurun waktu tertentu & 19 & 1 \\
\hline Saya tahu video pembelajaran & 20 & 0 \\
\hline Saya akan menggunakan video pmbelajaran dalam mengajar & 17 & 3 \\
\hline Saya bisa menggunakan aplikasi di smartphone untuk membuat video pembelajaran? & 20 & 0 \\
\hline Saya bisa membuat video pembelajaran? & 20 & \\
\hline
\end{tabular}

Secara umum PKM memberi pelatihan kepada guru Sekolah YPAC ini dapat dikatakan berhasil. Hal ini dapat dilihat dengan terpenuhi capaian-capaian yang digariskan. Beberapa komponen yang menjadi ukuran ketercapaian yaitu target jumlah peserta pendampingan, tujuan pelatihan, target materi yang telah direncanakan, dan kemampuan peserta dalam penguasaan materi.

Target peserta seperti direncanakan dalam situasi pandemi adalah 20 guru. Dalam pelaksanaannya, kegiatan ini diikuti seperti target yaitu 20 orang peserta. Angka tersebut menunjukkan bahwa kegiatan PKM ini dilihat dari jumlah peserta yang mengikuti dapat dikatakan berhasil.

Ketercapaian tujuan pendampingan secara umum sudah baik terlihat dari peserta yang mampu mengoperasikan aplikasi untuk membuat bahan ajar yang interaktif. Selain itu guru dapat mengembangkan dan kreatif dalam pembelajaran daring dengan membuat bahan ajar yang interaktif dan dapat berjalan dengan baik dalam proses pembelajaran selama pendampingan terjadi. Jadi dapat disimpulkan bahwa tujuan pendampingan ini dapat tercapai.

Ketercapaian target materi juga cukup baik. Materi pendampingan sudah disiapkan dan disampaikan dengan baik dan secara menyeluruh. Materi-materi itu adalah materi pengetahuan umum mengenai ICT dan membuat video, materi aplikasi yang digunakan 
untuk membuat bahan ajar, dan tuntunan praktik pengembangan aplikasi untuk membuat bahan ajar yaitu media pembelajaran dalam bentuk video.

Dan terakhir, dari segi kemampuan peserta dalam menguasai materi juga sangat berhasil. Hal ini dapat dilihat dari hasil pre-test dan posttest yang menunjukan bahwa pengetahuan para peserta sangat bertambah, baik itu dalam hal pengetahuan seputar ICT maupun dalam pembuatan video untuk media pembelajaran. Pada dasarnya semua guru memakai media pembelajaran dalam mengajar di Sekolah YPAC Palembang, tetapi tidak ada yang mengunakan video sebagai media pembelajaran. Hal ini dikarenakan mereka belum bisa membuat dan memakai video. Setelah pelatihan semua guru bisa menggunakan aplikasi di smartphone dan laptop untuk membuat video pembelajaran. Hampir semua (17 orang) nantinya akan menggunakan video buatan sendiri sebagai media pembelajaran. Ini menunjukan bahwa pelatihan pembuatan video untuk media pembelajaran sungguh berhasil. Semoga para guru komitmen dan konsisten untuk menggunakan video sebagai media pembelajaran. Jadi secara prinsip peserta mampu membuat video untuk media pembelajaran ICT tetapi perlu dilatih terus menerus. Diharapkan peserta tetap melanjutkan membuat video sendiri, tentu bila ada kesulitan tim dosen selalu siap mendampingi.

Di akhir pelatihan para peserta diminta masukan dan saran. Dari masukan dan saran yang disampikan sebagian besar mengharapkan kegiatan yang serupa agar dilakukan kembali agar memperoleh pengetahuan baru. Ini bisa juga menjadi indikasi keberhasilan yang nampak dalam antusias dan kepuasan mereka dalam pelatihan.

\section{SIMPULAN}

Berdasarkan hasil pelaksanaan kegiatan pengabdian kepada masyarakat dapat disimpulkan kegiatan PKM ini berhasil. Hal ini dibuktikan dengan tercapainya komponen yang menjadi target dan tujuan yaitu ketercapaian target jumlah peserta, ketercapaian tujuan pelatihan, ketercapaian target materi yang telah direncanakan, dan kemampuan peserta dalam penguasaan materi.

Dari kuisioner juga kelihatan peningkatan yang signifikan yang awalnya mereka tidak pernah menggunakan video untuk bahan ajar, sekarang mereka bisa membuat video dan mampu menerapkannya. Pelatihan pembuatan media pembelajaran ini telah menambah pengetahuan para guru di sekolah Yayasan Pembinaan Anak Cacat (YPAC) Palembang mengenai pembuatan bahan ajar berupa video sebagai media pembelajaran interaktif. Ini sangat membantu guru untuk menyampaikan materi mereka kepada peserta didik. Guru sendiri menjadi lebih kreatif dalam mengajar terutama dalam pembuatan media pembelajaran.

Kegiatan PKM ini perlu dilanjutkan dan ditingkatkan lagi untuk membantu para guru untuk menjadi lebih kreatif dan punya kemampuan dalam membuat media pembelajaran. Maka perlu adanya kerjasama dalam bentuk pembimbingan khusus secara berkesinambungan yang dilakukan oleh tim dosen dengan pengawasan pada periode tertentu sehingga lebih terkontrol dengan baik.

\section{UCAPAN TERIMA KASIH}

Kegiatan pengabdian ini dapat berlangsung atas dukungan dari berbagai pihak. Kami selaku tim pengabdian mengucapkan terima kasih kepada Universitas Katolik Musi Charitas yang telah mendukung kami dengan fasilitas dan dana yang diberikan, Sekolah YPAC Palembang yang bersedia menjadi mitra, tim LPPM UKMC yang menfasilitasi PKM ini, dan tim Abdimas UKMC yang mengijinkan kami untuk mempublikasikan hasil pengabdian kami. Berkat dukungan dan kerjasama semua pihak inilah PKM kami bisa terlaksana dengan baik sampai dipublikasikan.

\section{REFERENSI}

Alfiani, D., dkk. 2016. 'Pembelajaran Berbasis Video Untuk Anak Generasi Z'. Prosiding Inovasi Pendidikan di Era Big 
Jurnal Abdimas Musi Charitas

Volume 5, Number 2, 2021, 98-104

Data dan Aspek Psikologinya. ISSN: 25485407. PascaSarjana Universitas Negeri Malang.

Cholik, A., C., 2017. 'Pemanfaatan Teknologi Informasi dan Komunikasi untuk Meningkatkan Pendidikan Di Indonesia'. Syntax Literate; Jurnal Ilmiah Indonesia. Vol.2 No.6

Microsoft. Windows Movie Maker dilihat 28 Juni 2021. https://www.microsoft.com/enus/p/movie-maker-10-free.

Nurita,T. 2018. 'Pengembangan media pembelajaran untuk meningkatkan hasil belajar siswa', Misykat, Jurnal Ilmu-ilmu Al'Quran, Hadist, Syaria'ah dan Tarbiyah, ISSN: 2527-8371, dilihat 30 Juni 2021 https://pps.iiq.ac.id/jurnal/index.php/MISY KAT/article/view/52
Rival. (2016, 04). Definisi Movie Maker dan Menggunakan Movie Maker. Diambil kembali dari https://rivalsynyster.blogspot.com/2016/04/ definisi-moviemaker-danmenggunakan.html

Syahroni, M., Dianastiti, F.E., 2020 'Pelatihan Media Pembelajaran Berbasis Teknologi Informasi untuk Meningkatkan Keterampilan Guru dalam Pembelajaran Jarak Jauh', Ejournal Undiksha, article 28847

https://ejournal.undiksha.ac.id/index.php/IJ CSL/article/view/28847

Undang- Undang no. 8 Tahun 2016 mengenai penyandang disabilitas. 